\title{
The optical properties of Al doped zinc oxide films
}

\author{
Hongxia Dai \\ Computer Science and Information Engineering College of Chongqing Technology and Business \\ University , Chongqing 400067, China; email:dhx69@ctbu.edu.cn
}

\begin{abstract}
Keywords: nano-thin film photovoltaic materials; ; Doping ; optical properties
Abstract. the functional film is the development and application of nanotechnology, along with the development of computer, semiconductor, solar energy and other industries, a related functional materials -- transparent conductive oxide thin films produced, developed, researching on $\mathrm{ZnO}: \mathrm{Al}$ $\mathrm{ZnO}$ films doped with aluminum is the most widely. This article discusses the material preparation and optical properties of nano-optoelectronic thin films and the hexagonal wurtzite structure of $\mathrm{ZnO}$ : $\mathrm{AL} \mathrm{ZnO} \mathrm{films} \mathrm{,} \mathrm{and} \mathrm{points} \mathrm{out} \mathrm{the} \mathrm{application} \mathrm{value} \mathrm{and} \mathrm{the} \mathrm{existing} \mathrm{problems} \mathrm{of} \mathrm{ZnO}$ :Al thin films, and puts forward the research direction in the future.
\end{abstract}

\section{Introduction}

The functional film is the development and application of nanotechnology, and $\mathrm{ZnO}$-based thin films were developed in 1980's. For another kind of material, SnO2 thin films are transparent conducting films which acquired earliest commercial application[1], and are most extensively applying with high transmittance and electrical conductivity, has strong substrate adhesion and hardness. ITO thin films are indispensable transparent electrode materials of graphic liquid crystal display device, but the rare element Im has low stability in plasma of solar battery application and occupies a fraction of storage capacity in nature with higher price. At present, $\mathrm{ZnO}$-based thin films material performance are closely to ITO thin films with rapidly researching development, and among this kind of material, researching on $\mathrm{ZnO}$ films doped with aluminum is the most widely, this films prominent superiorities are reflected in the features of easy availability and low productive costing and enabled to produce complicated electrode with non-toxic, good adulteration, easy etching and stabilization in plasma. Therefore, this material is possible to become an substitute product of ITO thin films, especially in the field of transparent electrode of solar battery.

\section{Text structure of $\mathrm{ZnO}$ thin films}

$\mathrm{ZnO}$ thin films with open hexagonal structure, the component atoms with smaller radius easily become interstitial atoms, performance of films could be altered by adulteration of impurity elements such as $\mathrm{Al}$. $\mathrm{ZnO}$ film is a broad-band gap semiconductor, lattice constant of $\mathrm{a}=0.326 \mathrm{~nm}, \mathrm{c}=0.522 \mathrm{~nm}$, the width of band gap is about $312 \mathrm{eV}$, with good light transmittance in the visible light range, light transmission rate of $91 \%$, higher than the 10.68 resistivity.

\section{Optical properties of ZnO Nano thin-film photovoltaics}

$\mathrm{ZnO}$ nanowire arrays are launched in the wavelength of $383 \mathrm{~nm}$, line width of $0.3 \mathrm{~nm}$ near ultraviol et laser, and $\mathrm{ZnO}$ become a kind of applicable to broad-band gap compound semiconductor of black light electronic devices. For the target of optical enhancement in broad-band gap semiconductor mat erials, it must have high carrier concentration and electron hole pair form the laser emission. For the implement of effective laser emission in room temperature, the binding energy of electron hole pair must be much greater than thermal emission energy of $26 \mathrm{mV}$ in room temperature.In this regard, $\mathrm{Zn}$ $\mathrm{O}$ is an ideal material because of its excitation binding energy of $60 \mathrm{mV}$ greater than $\mathrm{ZnSe}$ of $22 \mathrm{mV}$ a nd $\mathrm{GaN}$ of $25 \mathrm{mV}$.

$\mathrm{ZnO}$ nanowire for light-induced laser emission produced by the growth processing of vapor transp orting of epitaxial crystal. $\mathrm{ZnO}$ nanowire arrays electron microscope image as shown ref-er with: Fig. 1, nanowire arrays of 20 to $150 \mathrm{~nm}$ and $95 \%$ of 70 to $100 \mathrm{~nm}$ diameter grow in the Au depositing are 
a only, and the reason for these different diameter is that basal annealing caused inconformity of nan o particle size. The length of nanowire could be varied in the range of 2 to $10 \mathrm{~nm}$ by adjusting growth time.The implement of templated nanowire growing make it possible to prodduce laser emission dev ices in the nanometer size by using a controllable way.

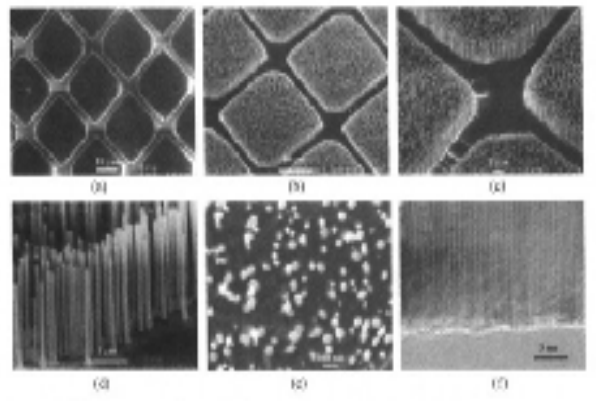

Fig 1 The electron microscope figure of $\mathrm{ZnO}$ nanowire arrays

Using $\mathrm{He}$ - Cd laser within wave length of $325 \mathrm{~nm}$ as excitation light source to measure PL spectr um of $\mathrm{ZnO}$ nanowire, and a strong near-band gap edge emission effected in the wave length of $377 \mathrm{n}$ $\mathrm{m}^{[2]}$, for detecting possible laser emission from these directionally grown nanowire by changing pum ping power to measure emission spectrum. Using quadruplicated frequency of $\mathrm{Nd}$ ji aluminium garn et laser with $266 \mathrm{~nm}$ wave lengths and 3ns pulse width as pump light source to radiate sample, and pu mping beam focus on the nanowire on the direction of 30 degrees with uranium of nanowire, collecti ng light and changing power of pump light on the vertical direction of nanowire terminal plane and varying emission spectrum constantly. Under this circumstance without any amplifying device, it coul $\mathrm{d}$ been seen that $\mathrm{ZnO}$ nanowire arose laser emission as fig $2 \mathrm{a}$ and $\mathrm{b}$ shown. When pumping light int ensity is lower, emission spectrum has only spontaneous emission peak with $17 \mathrm{~nm}$ half-width and th e spontaneous emission energy of $140 \mathrm{meV}$ less than energy gap of $3.37 \mathrm{eV}$.Commonly,because of the photons by radiation of recombination between elicitors, and with rising power of pumping light, the peak width is more narrow. When the stimulating intensity exceeds closed value $\left(40 \mathrm{~kW} / \mathrm{cm}^{2}\right)$, sharp peak happens on the emission spectrum(See curve 2 of fig 2.a), and peak value appears at the wave 1 ength of $383 \mathrm{~nm}$ and line width of peak is less than $0.3 \mathrm{~nm}$ that less than 50 times of spontaneous emi ssion peak width under the excitation threshold value. When stimulating intensity exceeds excitation threshold, the entire emission intensity increase rapidly with the power enlargement of pumping light, as shown as fig 2.b. The extremely narrow peak width and rapidly increasing emission intensity expl ain laser emission in $\mathrm{ZnO}$ nanowire, and single and multiple peaks from observation respectively rep resent different emission pattern in wavelength range of 370 to $400 \mathrm{~nm}$.

Observing laser emission of this nanowire without any amplifying device urge us to believe this mo nocrystalline nanowire with good transverse plane could be natural cavity as shown as fig.2.c.This $\mathrm{p}$ hoto-enhancement effect happens only in high-quality nanowires crystal, it will cause nanowires arra ys to have laser emission in elicitors with nanowires diametral size bigger than bohr radius but less $t$ han wavelength.

\section{Optical-electrical characteristic of $\mathrm{ZnO}$ :Al thin films}

The most remarkable feature of $\mathrm{ZnO}: \mathrm{Al}$ thin films is the current-ilumination characteristic, low-re sistance, high transmittance for visible light and high reflectance for infrared light, and electricity an d optical properties of $\mathrm{ZnO}: \mathrm{Al}$ thin films are intrinsically internally linked. 


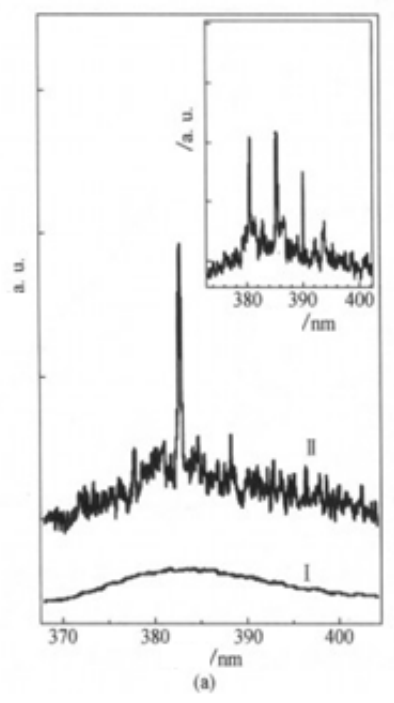

Fig.2
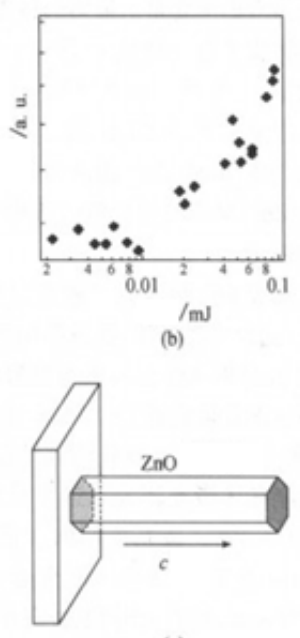

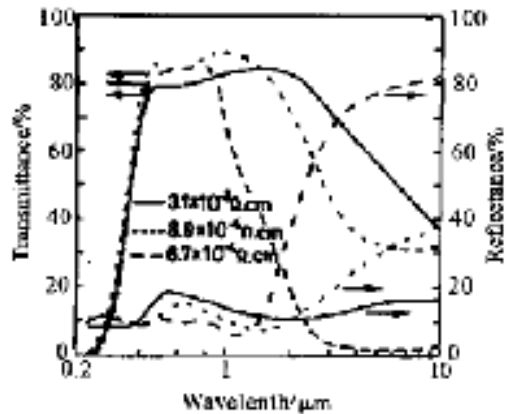

Fig 3

Fig.2 The photoinduced laser emission of $\mathrm{ZnO}$ nanowire

Fig 3 Transmittance and Reflectance of $\mathrm{ZnO}$ thin films in different resistivity

$\mathrm{ZnO}: \mathrm{Al}$ thin films electrical properties has a lot to do with oxygen deficiency and adulteration. con duction electrons of $\mathrm{ZnO}$ : $\mathrm{Al}$ thin films could be produced from replacement of $\mathrm{Al}^{3+}$ to $\mathrm{Zn}^{2+}$ and oxyg en atoms omission. Oxygen vacancy and adulteration of Al atoms are donor atoms to produce amass of free electron and carrier in high concentration. But when 12 surrounding lattice oxygen ions of an oxygen vacancy have more than one oxygen vacancy, it means content of oxygen vacancy reached $2 /$ $(12+1)=2 / 13$, in this case, lattice distortion seriously caused structural instability, destroyed crystallin ity, could not improve conductivity. On the basis of Zhi-Xin Fan's carrier concentration model of Zn O:Al thin films:

$$
n=-\left[1-x\left(\frac{z+1}{2}\right) e^{\frac{\Delta E}{k T}}\right] \frac{N_{A}}{V_{m o l}}
$$

Above this formula, $\mathrm{Z}$ is the coordination number of 12 average between $\mathrm{Zn}^{2+}, x=N_{\mathrm{Al}} /\left(N_{\mathrm{Al}}+N_{\mathrm{Zn}}\right)$ is $\mathrm{Al}$ adulteration content percentage, $x(Z+1) / 2$ is doping failure percentage(connot contribute carrie $\mathrm{r}$ ), $\mathrm{k}$ is Boltzmann constant, $\mathrm{T}$ is Thermodynamics absolute temperature, corresponding an equivalent temperature between target source and placode, $\triangle E$ is the heat energy change of sputtering atoms fr om the three-dimensional gas to two-dimensional gas membrane surface, and $N_{\mathrm{A}}$ is Avogadro's const ant, $V_{\text {mol }}$ is the molar volume of $\mathrm{ZnO}$ in thin films. The physical significance of above-mentioned mo del could be comprehended in that: When $\mathrm{Al}$ doping content is low, andcarrier concentration in prop ortion to doping content increasing. And when Al doping content is close to $\mathrm{x}=2 / 13, \mathrm{Al}$ atoms and ox ygen atoms have greater opportunity to compose into $\mathrm{Al}_{2} \mathrm{O}_{3}$ and it causes reduction of redundant elec tronics. And this model reflects capacity of decreasing of carrier concentration.

From the construction of $\mathrm{ZnO}: \mathrm{Al}$ thin films, it could be seen that when the surrounding next neare st neighbor of 12 zinc ionic lattices of an $\mathrm{Al}$ displacement ion still have an $\mathrm{Al}$ displacement ion, the prabability of two $\mathrm{Al}$ ion and three oxygen ion to meet and form $\mathrm{Al}_{2} \mathrm{O}_{3}$ will increase, as a result, cond uctivity will descend. Improper control of $\mathrm{Al}$ doping concentration and oxygenflow will cause $\mathrm{Al}_{2} \mathrm{O}_{3}$ phase exists in thin films and greatly reduce carrier concentration and mobility ratio in thin films, fin ally descend thin films electrical property. Therefore, with the target of producting high-quality $\mathrm{ZnO}$ : $\mathrm{Al}$ thin films, $\mathrm{Al}$ doping concentration and oxygenflow must be controlled strictly for avoiding $\mathrm{Al}_{2} \mathrm{O}_{3}$ phase exists $^{[3]}$.

From researching, high-temperature in-situ synthesis and anneal could dramaticlly reduce electrical 
resistivity of $\mathrm{ZnO}: \mathrm{Al}$ thin films. (in fig.3.By below, ) Because of the formation from the replaceme nt of $\mathrm{Al}^{3+}$ to $\mathrm{Zn}^{2+}$ between interstitial atoms and oxygen vacancies ${ }^{[4]}, \mathrm{ZnO}$ :Al films conductivity is su perior to pure $\mathrm{ZnO}$ films, and with the increase in content of $\mathrm{Al}_{2} \mathrm{O}_{3}$, the carrier concentration of $\mathrm{ZnO}$ : $\mathrm{Al}$ films augment and the maximum is $7.5 \times 10^{20} \mathrm{~cm}^{-3}$. Using $\mathrm{ZnAl}$ with containing $3 \%$ mass fraction of $\mathrm{Al}_{2} \mathrm{O}_{3}$ to produce $\mathrm{ZnO}$ : Al thin films with electrical resistivity of $4.7 \times 10^{-48} \Omega \cdot \mathrm{cm}$, transmittivity of $\mathrm{ZnO}: \mathrm{Al}$ films over $90 \%$. But When $\mathrm{Al}_{2} \mathrm{O}_{3}$ phase exists in films, carrier concentration and mobility ra tio will be reduced greatly and its electrical properties will be impaired. ${ }^{[5]}$

$\mathrm{Al}$ doping content has less influence to light transmittance of $\mathrm{ZnO}$ :Al thin films, but films energy gap will increase as Al doping concentration increase, optical absorption edge moves to short wave with an absorption limit of ultraviolet ending position. Due to the substitution doping for $\mathrm{Al}^{3+}$ to $\mathrm{Zn}^{2}$ ${ }^{+}$, carrier concentration raise in films, and make the enhancive carrier fill in the low level of conducti on band and electrons from valence band jump into the high level of conduction band so that films a bsorption edge move in the direction of short wave. But with the limited solubility of $\mathrm{Al}$ in $\mathrm{ZnO}$ thin films, Al adulteration achieves a certain level, carrier concentration will be saturated and the moving of absorption edge go to the same limit. Drude Theory obeying relectivity of $\mathrm{ZnO}$ :Al thin films to inf rared light, it means reflectivity $\mathrm{R}$ could be expressed as $R$, is permittivity vacuum, c refers to speed of light in the vacuum, e refers to electron charge, $n$ is carrier concentration, $d$ is film thickness, is mobility ratio of carrier in films and $R$ is square resistance. So thin films infrared reflectivity increasi ng while square resistance decreasing or film thickness increasing. Therefore, the effect of Al adulter ation must be researched on the basis of requirement of reflectivity and transmittivity with different application purpose.

\section{Conclusion}

Taking into consideration of extensive potential application value of $\mathrm{ZnO}$ : $\mathrm{Al}$ thin films, it is an ap proach of deep processing application of common metal $\mathrm{Zn}$ and have increasing attention with widel $y$ researching. But its properties uniformity, technical stability and repeatability still need improving with large area of high uniform film-forming process and lithography process compability being reso lved. Pay more attention to research on Preparation of magnetron sputtering process and Substrate su rface chemical reaction mechanism, systematically in-depth analysis the influence of temperature, at mosphere, magnetic field intensity and gas pressure to film forming speed, film chemical component and adhesive force and optical-electrical characteristic, could solve the problems of $\mathrm{ZnO}$ :Al thin fil ms and successfully accomplish industrialization.

\section{References}

[1] Zhang Q F , Pan G H, Den N, et al.Proc. 6th IEEE Chin.. Optoelectr. Symp., Hong Kong,2003

[2] Huang M H ,Wu Y,Feick H ,et al.Adv.Mater.,2001,13(2):113

[3]Yu P,Tang Z K,Wong G K L,et al.J.Cryst.Growth,1998,184/185 : 601

[4]Kim K H, Park K C,M a D Y. Structural, exletrical and op ticalp roperties of alum inum doped zinc oxide film sp repared by radio frequency magnetron sputtering [J ]. J. App lied Phys. , 1997, 81(12) : 7764- 7772 .

[5] Kw royanmagiA. Crystallograph ic characteristics and electricalp roperties of A 12doped $\mathrm{ZnO}$ th in film s p repared by ionized deposition[J]. J. App 1. Phys. , 1989, 66 (11) : 5492- 5497. 